\section{Statistical Papers}

Statistical Papers of George Udny Yule. Selected by Alan Stuart and Maurice G. Kendall. Pp. viii +447 . (Charles Griffin: London, August 1971.) £6.90. George UdNY Yule, who was born in 1871 and died in 1951, was certainly a peer of the statistical realm. Some knew him as one of England's gentlemen but many more as an innovator of statistical techniques and a teacher of great capability and understanding. The book by which he will be known to most (and recalled with gratitude) is the Introduction to the Theory of Statistics, first published in 1911 and still in substantial demand with the fourteenth edition (1950) being the fourth in collaboration with Dr M. G. Kendall, one of the selectors for the volume now under consideration. To say "review" would be impertinent as well as discourteous, therefore let it be stated that the distinguished selectors have carried out with great understanding their difficult task of exclusion: the complete bibliography shows their problem clearly.

To quote from the preface, "The reason why these twelve papers were selected ... is that they contain work whose historical significance in the development of statistical methods is matched by its continuing importance". To the selected papers is added the account of the man written by $\mathrm{Dr}$ Kendall (J. Roy. Statist. Soc., A, 115, 156 ; 1952). The selected papers fall into three groups : theory of association and correlation, epidemiological studies and the analysis of time series.

The first group (1900, 1903, 1907 and 1912) form the basis of current practice especially with respect to the difficult problem of notation. In fact, Yule's work on measures of association between attributes is still the principal reference and it is of importance to current and future generations of students that they should know that the date is not significant in any sense of being old and out of date. The selectors note that these four papers do not exhaust Yule's work in this field and an item drawn from the bibliography "On the interpretation of correlations between indices and ratios" (J. Roy. Statist. Soc., 73, $644 ; 1910$ ) is of considerable importance in economic assessment.

The second group (1910, 1915, 1917 and 1920) are in the field of epidemiology but they contain the fundamental work (jointly with the late Professor Major Greenwood) on the negative binomial distribution; a form which has very wide-ranging applications both as a logical model and as a descriptive device. Moreover the 1910 paper is an early example of what is now known as sequential analysis and the 1920 paper is an original example of mixtures of distributions upon which a great deal of more recent work has taken place.

The third group (1921, 1926, 1927 and $1945)$ are on the analysis of time series whereas the philosophy of serial correlation, the correlogram and the autoregressive series (as a stochastic model) is set against that of classical harmonic analysis. This step is now seen to have been vital for the understanding of economic and social activities where man's memory plays an important part.

Looking back it is interesting to see the time sequence of these three groups; interspersed in these is a range of other papers, including all Yule's work on the statistical analysis of literary style and vocabulary, which should also not be overlooked by teachers, students, research workers and practising statisticians now and in the future. The selectors and publishers are to be congratulated and commended on this volume to celebrate the centenary of Yule's birth.

W. R. BUCKLAND

\section{Postal History}

History of Letter Post Communication Between the United States and Europe, 1845-1875. By George E. Hargest. (Smithsonian Studies in History and Technology, No. 6.) Pp. ix +234 . (Smithsonian Institution: Washington, 1971.) $\$ 4.25$.

ON reading the title of this book two questions immediately spring to mind: why 1845 and why 1875 ? The answer to the first is tied up with the trade and business rivalry between the United States and Great Britain. A British steamship line (Cunards) had become so efficient that their regular fourteen-day service between Boston, Massachusetts, and Liverpool (the "Atlantic Shuttle") had forced the American sailing packets well into second place. The British ships carried the mail, cabin passengers and "fine" freight; the Americans carried the coal. American pride was piqued and Congress was concerned about the security aspect of all the American mail to Europe being carried by British ships. In 1845 an act of Congress was passed subsidizing the United States mail packet ships, in an attempt to overcome British domination of the Atlantic service.

Why 1875 ? To answer this we have to go back to the time before the General Postal Union. Then a letter from the
United States to Europe could not be fully prepaid, some of the postage had to be paid in the United States and some in Europe. When a postal convention existed, accounting between the post offices of the contracting countries was established which made it possible to pay the whole postage on a letter sent or received. On January 1, 1876, France, the last of nineteen European countries to do so, placed in force the provisions of the treaty of Berne and became an active member of the GPU.

The history of the letter post communication between the United States and Europe between the years 1845 and 1875 is told in this book. It is divided into sections describing the negotiations of the United States-Bremen, Germany, Postal Arrangement of 1847; the postal treaty with Britain (December 1848); postal relations with France, and the United States-French Postal Convention of March 1857; the Prussian Closed Mail Convention; postal relations with Belgium 1844-1868; amendments in the 1860 s to the above convention and the operations of the steamship lines; postal conventions effective after January 1, 1868; postal relations with France 1870-1876; depreciated currency covers and finally the postal rates between the United States and all foreign countries.

The book is obviously the result of much painstaking research, largely drawn from primary sources. It contains many illustrations of postal covers ("the cover being to the postal historian what the artifact is to the archaeologist") and is very well indexed. It makes a worthy addition to any postal historian's bookshelf.

David W. Hughes

\section{Old Affinity}

Affinity and Matter. By Trevor $\mathrm{H}$. Levere. Pp. xvii $+230+14$ plates. (Clarendon: Oxford; Oxford Uni. versity: London, September 1971.) $£ 4.50$.

LEVERE opens this book with an excellent chapter summarizing the major eighteenth century views on affinity Then follow the four principal chapters chiefly concerned with setting out the speculative views of Humphry Davy Michael Faraday, Jöns Jakob Berzeliu and Hans Christian Oersted. The fina two chapters respectively describe thi input from the rapidly growing field o organic chemistry, and the mid-centur! anticipations of what became thermo dynamics. The first chapter and thi last two thus provide a historical settin! for the author's major concern to dis 